\title{
Hepatosplenic shear wave elastography for prediction of esophageal varices in cirrhosis: a promising future?
}

\author{
Ana Cristina Santos de Paula Pessoa ${ }^{1 *} \mathbb{0}$, Carlos Antonio Bruno da Silva ${ }^{1}$
}

The liver is the largest solid organ of the human body, corresponding to $1 / 34$ of total body weight. It has several metabolic functions, including processing, storing, and redistributing biomolecules such as glucose, amino acids, and fatty acids. In addition, the liver acts in immunological processes and the metabolization and elimination of drugs and hormones; it also has valuable regenerative capacity. Due to its importance, acute or chronic hepatic lesions may cause several diseases ${ }^{1}$.

Cirrhosis is defined as the final stage of chronic liver disease (CLD). It results from constant and progressive aggression to the liver and is characterized by fibrosis, with the conversion of the normal liver architecture into regenerative nodules and subsequent distortion of the organ lobular and vascular architecture. There are several etiologies, such as steatohepatitis, viral hepatitis, excessive alcohol consumption, obstruction of the circulation through the suprahepatic veins and inferior vena cava, metabolic and autoimmune liver diseases, and structural changes of the bile ducts. As the condition progresses, liver failure (LF) and portal hypertension $(\mathrm{PH})$ might occur ${ }^{2-4}$. Of the numerous causes that lead cirrhotic patients to emergency services, variceal upper digestive hemorrhage (VUDH), spontaneous bacterial peritonitis (SBP), hepatic encephalopathy (HE), ascites, pleural effusion, and LF are the most common ones. These complications occur due to $\mathrm{PH}$ and/or LF and may be a natural progression of the disease or result from decompensation by a precipitating factor, such as bleeding, infection, alcohol and/ or drug abuse, dehydration, or constipation ${ }^{2}$.

Variceal digestive hemorrhage is an important cause of mortality in patients with PH. Studies show that up to 60 and $30 \%$ of patients with decompensated and compensated cirrhosis, respectively, present with esophageal varices $(\mathrm{EV})$ at the time of diagnosis. All patients with cirrhosis should undergo evaluation for $\mathrm{EV}$, i.e., an esophagogastroduodenoscopy (EGD). However, besides being an invasive procedure, EGD is costly since it requires sophisticated equipment, sedation, and trained staff 5 . As such, several noninvasive methods for EV diagnosis have been proposed, including the platelet/spleen ratio. Similarly, elastography has successfully measured liver and spleen stiffness. Initially, the transient technique (FibroScan ${ }^{\circledR}$ ) was studied before the investigation of acoustic radiation force impulse (ARFI) and shear wave elastography (SWE) ${ }^{7}$.

Some studies on liver and spleen elastography show the satisfactory identification of varices. However, this method evaluates only the mechanical properties of the liver or spleen and does not provide information on the hemodynamics related to the development of varices. Several studies corroborate the correlation between increased liver stiffness and the presence of large varices ${ }^{8}$.

Ultrasound elastography is a noninvasive method for the diagnosis of tissue stiffness which is determined by measuring the propagation speed of ultrasound waves through the organ. The software is coupled with the multidisciplinary ultrasound equipment, and ARFI is applied to the region of interest, usually segments V and VIII, with the transducer positioned between intercostal spaces. As for the spleen, the inferior pole is the region of interest during the examination, with a positioning technique similar to the one used for the liver. Standardization allows more accurate measurement, reducing interobserver variation and increasing reproducibility. The more stiffened the organ due to fibrosis progression, the higher the

'Universidade de Fortaleza - Fortaleza (CE), Brazil.

*Corresponding author: crispessoa2011@gmail.com

Conflicts of interest: the authors declare there is no conflicts of interest. Funding: none.

Received on March 21, 2021. Accepted on May 02, 2021. 
wave propagation speed. The result is determined by the pressure measured in $\mathrm{kPa}$ (kilopascal), while the speed is measured in meters per second $(\mathrm{m} / \mathrm{s})^{9-11}$.

Kim et al. ${ }^{12}$ conducted a study in South Korea with 103 patients to evaluate the diagnostic performance of SWE in predicting the presence of $\mathrm{EV}$, including high-risk $\mathrm{EV}$, in patients with compensated cirrhosis, besides comparing it with other nonspecific predictors and the presence of splenomegaly. The authors concluded that hepatic stiffness measured by SWE is an effective noninvasive diagnostic tool to predict the presence of $\mathrm{EV}$ and proved to be more accurate than the platelet/spleen ratio, especially in patients without splenomegaly. They also described SWE as the only effective independent factor for predicting high-risk EV.

In Egypt, Hashim et al. ${ }^{6}$ performed SWE in 100 patients with cirrhosis due to hepatitis $\mathrm{C}$ through the measurement of the liver (LS) and spleen (SS) stiffness. The same patients underwent upper digestive endoscopy to evaluate for EV. The authors reported a significant difference in LS and SS between patients with and without varices $(\mathrm{p}<0.001)$. LS measurement at the $16.2 \mathrm{kPa}$ cutoff and SS measurement at the $42.7 \mathrm{kPa}$ cutoff by elastography predicted the presence of varices with 89.8 and 94.9\% sensitivity, respectively, and 57.6 and $87.9 \%$ specificity, respectively. Cutoff points of 19.6 for LS and $51.5 \mathrm{kPa}$ for SS predicted a high risk for EV with 77.5 and $85 \%$ sensitivity, and 63.4 and $84.6 \%$ specificity, respectively. Results showed that elastography was more sensitive and specific in identifying the presence and risk of EV for SS than LS.

In Rome, Gibiino et al. ${ }^{13}$ conducted a systematic review with studies measuring spleen stiffness by elastography to evaluate adults with hepatic and non-hepatic $\mathrm{PH}$. The results were organized using transient elastography and shear wave elastography. Almost 20 studies were included, wherein elastographic techniques were compared with the measurement of the hepatic venous pressure gradient, which is the gold standard for the diagnosis of PH. In general, spleen stiffness measurement showed good diagnostic accuracy for clinically significant PH in CLD, with reliable cutoff values for severe $\mathrm{PH}$ in some cases. The authors concluded that spleen elastography can be an accurate noninvasive tool to assess the presence of $\mathrm{PH}$. However, the technical differences available for evaluation and the various cutoff values may still limit its use in clinical practice.

In Egypt, Dwidar et al. ${ }^{14}$ studied 120 patients with CLD undergoing SWE and endoscopy and correlated the data of organ stiffness with the presence of varices; the authors found that liver measurement was better than spleen measurement in predicting varices with cutoff values of 10.3 and $18.25 \mathrm{kPa}$, respectively. However, spleen measurement was superior in grading varices, presenting cutoff values of 19.62 and $14.21 \mathrm{kPa}$ for grade II varices and 28.75 and $15.6 \mathrm{kPa}$ for grade III varices. They concluded that hepatosplenic elastography can be considered a noninvasive choice for varix screening, leaving digestive endoscopy for patients requiring intervention.

In Bucharest, Fierbinteanu-Braticevici et al. ${ }^{7}$ analyzed 135 patients with cirrhosis using clinical examination, laboratory tests, abdominal ultrasound, LS and SS evaluation, and upper digestive endoscopy. For endoscopy, the patients were classified into three groups: no evidence of EV, small-caliber varices, and varices requiring treatment. Patients with $\mathrm{EV}$ of any degree had significantly higher mean SS values than those with no $\operatorname{EV~}(3.37 \mathrm{~m} / \mathrm{s}$ versus $2.79 \mathrm{~m} / \mathrm{s}, \mathrm{p}<0.001)$, similarly patients with varices requiring treatment had significantly greater mean SS values than those who did not need treatment $(3.96 \mathrm{~m} / \mathrm{s}$ versus $2.93 \mathrm{~m} / \mathrm{s}, \mathrm{p}<0.001)$. Elastographic spleen measurement was proved to be an excellent method for predicting patients with varices requiring treatment.

Patients without splenomegaly are difficul to assess using SWE. Procopet et al. ${ }^{15}$ reported failure in up to $40 \%$ of those examined. This problem is minimized with adequate training, examiner experience, and innovative technology, even if these come from different manufacturers ${ }^{13,15}$.

In São Paulo, Ramos ${ }^{5}$ conducted a study evaluating the accuracy of elastography techniques (FibroScan ${ }^{\circledR}$ and ARFI) in predicting EV and their risk of bleeding in patients with non-cirrhotic portal hypertension. Splenic elastography by FibroScan ${ }^{\circledR}$ with a cutoff point of $65.1 \mathrm{kPa}$ showed an accuracy of $0.62(95 \% \mathrm{CI}$ $0.46-0.78 ; \mathrm{p}=0.121)$ for the presence of varices. In the prediction of varices at a high risk of bleeding, the best cutoff point was $40.05 \mathrm{kPa}$, which showed an accuracy of 0.63 (95\%CI $0.52-$ $0.76 ; \mathrm{p}=0.016$ ). Splenic ARFI elastography with a cutoff point of $2.67 \mathrm{~m} / \mathrm{s}$ showed an accuracy of 0.64 (95\%CI $0.50-0.78$; $\mathrm{p}=0.065$ ) for the presence of varices. For those with a high risk of bleeding with this method, the cutoff point was $3.17 \mathrm{~m} / \mathrm{s}$, with an accuracy of $0.61(95 \% \mathrm{CI} 0.51-0.71 ; \mathrm{p}=0.033)$. The author concluded that splenic elastography methods showed moderate accuracy and high positive predictive value in diagnosing the presence of varices. When splenic elastography by FibroScan was associated with platelet/spleen ratio, a moderate accuracy with high specificity was evidenced to predict varices with high risk of bleeding. The same author indicated an overlap of values between patients with and without $\mathrm{EV}$, which may limit the application of this method in clinical practice.

This study concluded that hepatosplenic SWE is a safe, low-cost, noninvasive, and easily reproducible method for EV prediction. It may be exceedingly useful in the screening and follow-up of cirrhotic patients, allowing for the avoidance of serial digestive endoscopies. However, this requires further studies to validate an appropriate cutoff point. 


\section{AUTHORS" CONTRIBUTIONS}

ACSSPP: Conceptualization, Data curation, Formal analysis, Investigation, Methodology, Project administration, Resources, Software, Supervision, Validation, Visualization, Writing - original draft, Writing - review \& editing. CABS: Conceptualization, Data curation, Formal Analysis, Investigation, Methodology, Project administration, Resources, Software, Supervision, Validation, Visualization, Writing - original draft, Writing - review \& editing.

\section{REFERENCES}

1. Santos AA, Lima JMC. Fisiologia hepática. In: Oriá RB, Brito GAC. Sistema digestório: integração básico-clínica. São Paulo: Blucher; 2016. p. 575-602. https://doi.org/10.5151/9788580391893-21

2. Bittencourt PL, Zollinger CC, Coelho HSM. Manual de cuidados intensivos em hepatologia. Barueri: Manole; 2014.

3. Lima JMC, Costa JIF, Santos AA. Gastroenterologia e hepatologia: sinais, sintomas, diagnóstico e tratamento. $2^{\mathrm{a}}$ ed. Fortaleza: Edições UFC; 2019

4. Silveira, LR, Iser BPM, Bianchini F. Fatores prognósticos de pacientes internados por cirrose hepática no sul do Brasil. GED Gastroenterol Endosc Dig. 2016;35(2):41-51.

5. Ramos DS. Elastografia hepatoesplênica para predizer varizes esofágicas em pacientes com hipertensão portal não cirrótica: estudo de acurácia diagnóstica [dissertação]. São Paulo: Universidade de São Paulo, 2018.

6. Hashim AEM, Shakweer MM, Attia FF, Awadallah HM, Elraaey FM, Ibrahem AM. Measurement of liver and spleen stiffness by shear wave elastography as a noninvasive evaluation of esophageal varices in hepatitis $C$ virus-related cirrhosis. Al-Azhar Assiut Medical Journal. 2017;15(2):111-6. https:// doi.org/10.4103/AZMJ.AZMJ_43_17

7. Fierbinteanu-Braticevici $C$, Tribus $L$, Peagu $R$, Petrisor $A$, Baicus C, Cretoiu D, et al. Spleen stiffness as predictor of esophageal varices in cirrhosis of different etiologies. Sci Rep. 2019;9(1):16190. https://doi.org/10.1038/s41598019-52407-y

8. Karatzas A, Konstantakis C, Aggeletopoulou I, Kalogeropoulou C, Thomopoulos K, Triantos C. Non-invasive screening for esophageal varices in patients with liver cirrhosis. Ann Gastroenterol. 2018;31(3):305-14. https://doi.org/10.20524/ aog.2018.0241
9. Silva LCM, Oliveira JT, Tochetto S, Oliveira CPMS, Sigrist R, Chammas MC. Análise da elastografia por ultrassonografia em pacientes com esteatose hepática. Radiol Bras. 2020;53(1):4755. https://doi.org/10.1590/0100-3984.2019.0028

10. Brasil. Agência Nacional de Saúde Suplementar. Nota Técnica n ${ }^{\circ}$ 196/2017 Revisão do Rol de Procedimentos e Eventos em Saúde - 2018. Processo n 33902.440494/2016-22. Available from: http://www.ans.gov.br/images/stories/Particitacao_da_ sociedade/consultas_publicas/cp61/cp61_relatorio_nota_ tecnica_196_2017.pdf

11. Giuffrè $M$, Macor $D$, Masutti $F$, Abazia $C$, Tinè $F$, Patti $R$, et al. Evaluation of spleen stiffness in healthy volunteers using point shear wave elastography. Ann Hepatol. 2019;18(5):736-41. https://doi.org/10.1016/j.aohep.2019.03.004

12. Kim TY, Kim TY, Kim Y, Lim S, Jeong WK, Sohn JH. Diagnostic performance of shear wave elastography for predicting esophageal varices in patients with compensated liver cirrhosis. J Ultrasound Med. 2016;35(7):1373-81. https://doi.org/10.7863/ultra.15.07024

13. Gibiino G, Garcovich M, Ainora ME, Zocco MA. Spleen ultrasound elastography: state of the art and future directions - a systematic review. Eur Rev Med Pharmacol Sci. 2019;23(10):4368-81. https://doi.org/10.26355/eurrev_201905_17944

14. Dwidar A, Samy W, Tawfik MA, Omar H, Harras F. Liver and spleen stiffness by shear wave elastography for a noninvasive evaluation of esophageal varices in chronic liver disease Patients. Life Science Journal. 2019;5(16):47-55. https://doi. org/10.7537/marslsj160519.07

15. Procopet B, Berzigotti A, Abraldes JG, Turon F, Hernandez-Gea V, García-Pagán JC, Bosch J. Real-time shear-wave elastography: applicability, reliability and accuracy for clinically significant portal hypertension. J Hepatol. 2015;62(5):1068-75. https:// doi.org/10.1016/j.jhep.2014.12.007 